\title{
Creating opportunities for exploration by modularizing a three credit engineering course
}

\author{
Rebecca O'Connell, Iowa State University \\ Gloria Starns, Iowa State University
}

\begin{abstract}
We describe the processes of collaboration and coordination that is necessary to break a traditional three credit course into a series of three one credit courses that allow students to meet the same course requirement. Students taking the course will be able to choose from a set of one-credit options for the third course in the sequence, allowing pursue their interests while still learning a common set of skills. ME 325, Mechanical Component Design, is a foundational course in mechanical engineering that is required in every accredited engineering program. While the course contains a common core that every mechanical engineering student should know, it continues on into specialized topics. Which of those specialized topics are taught in a particular section of ME 325 currently varies from section to section, depending on the instructor's areas of expertise. Breaking ME 325 into three one credit courses and adding a set of electives allows students to broaden their knowledge or focus on a specific area of interest. Single section offering might also be of interest to people in industry and others who simply need to review specific content areas. This essay explores what processes of communication and coordination are necessary to make this course format work and how to implement these processes in a way that ensures that the course is sustainable and cohesive.
\end{abstract}

\section{Introduction}

ME 325, Mechanical Component Design, is a foundational course in mechanical engineering that is required in every accredited mechanical engineering program. While the course contains a common core that every mechanical engineering student should know, it continues on into specialized topics. As part of our effort to move this course online, we are breaking the course three one-credit modules, each focusing on specific subtopic. Breaking ME 325 into three one credit courses and adding a set of electives allows students to broaden their knowledge or focus on a specific area of interest. Single section offerings might also be of interest to people in industry and others who simply need to review specific content areas.

While modularizing a course such as ME 325 has undeniable advantages, there are also issues that need to be addressed before it can be done effectively. While the course design of an inperson course taught in a classroom may be primarily the work of a single instructor, a modular online course usually requires collaboration between multiple instructors and with between instructional designers and experts in instructional technologies who assist with the process of producing and delivering a course. In this essay, we will explore the process of collaboratively 
developing a modularized online course, and some issues that arise during the development process.

\section{Establishing the Course}

The process of creating the modularized course began with Dr. Starns submitting a proposal to the director of undergraduate studies, who approved a pilot program. Once the pilot was approved, Dr. Starns put in an application for an Engineering-LAS Online course development grant. Once the grant was awarded, the lead instructor and the instructional design team met to plan how to go forward.

We structured our work together using the Analysis, Design and Development, and Evaluation cycle that is used as the standard design process for all Engineering-LAS Online courses. This process is a modified version of the popular ADDIE (Analyze, Design, Development, Implementation, Evaluation) instructional design framework. What makes it different is that in our modified approach there will be multiple iterations of the Analysis, Design and Development, and Evaluation cycle.

In the case of ME 325, a graphic designer and an instructional designer created a visual identity for the course and established a course website with common supporting materials such as information about how to use the course website, and how to find technical assistance, while an initial round of course materials for the first two modules, and one version of the third module, was developed by Dr. Starns. Dr. Starns then piloted those materials with four advanced students, and worked one-on-one with them to ensure that they were able to meet the learning objectives, while development continued on a fully developed version of the course site.

When the modules are officially offered, we will put in a request with the registrar to create three one credit modules.

\section{About the Course Modules and Course Sequences}

A full ME 325 three-credit sequence will typically consist of two analytical courses and a design course. Each sequence will need to meet the ABET requirements for the course.

\section{Meeting ABET Requirements}

This course is required to meet two ABET requirements. These are:

- "An ability to design a system, component, or process to meet desired needs within realistic constraints such as economic, environmental, social, political, ethical, health and safety, manufacturability, and sustainability"

- "An understanding of professional and ethical responsibility"1 
In order to meet the first ABET outcome for the course, students will be required to take at least one design-based course module that assesses students' abilities to design a mechanical system and analyze system components. Students would meet this ABET outcome by completing a project related to the topic of the module. This module would typically come at the end of a three module course sequence. The second outcome for the course would typically be met by specific assignments within the analytical prerequisite modules.

Instructors teaching modules within ME 325 would be responsible for ensuring that the course would meet the core ABET requirements, and for maintaining a list of other ABET requirements met and what specific components of the module are meeting them. This would assist in coordinating efforts to meet $\mathrm{ABET}$ requirements both within the course and within the department as a whole.

\section{Designing Course Sequences}

Design modules will have different prerequisites depending on the subject matter of the module. For example, a design module related to power trains might require a module that covers design and analysis of gearing, whereas a design module related to chassis design might have a prerequisite of a module covering vibrations and kinematics. Design modules will have at least one analytical prerequisite. The prerequisites would ensure that students are prepared for the design module that they choose to take.

One issue with this is ensuring that prerequisites for design modules are available. Prerequisites covering content typically covered by ME 325 would likely be available on a consistent basis, but content covering more specialized topics would be problematic. More specialized courses would typically be offered in sequences in which prerequisites are available in the semesters prior to the design course.

Most modules will be analytical in nature; content would be typical of that experienced in selection of machine components. The design modules will be more open-ended and dependent on coverage of topics in existing modules.

\section{Ensuring that Students are Prepared to Take the Course}

Prerequisites and pretests would be important tools for ensuring that students are fully prepared to take the course. As mentioned above, ME 325 design modules would have prerequisite models that would prepare them for the specific project they would be undertaking. Students would need to be carefully advised to ensure that they take the courses they need in sequence, and they would also need to be advised to take their courses within a specific time period. Pretests that students could take before enrolling would help students who have a time gap between modules 
and students who are not enrolled in the home university's degree program assess how prepared they are to take a module.

\section{Staffing Courses}

Ideally, several instructors would be working together, exploiting their areas of interest and expertise to offer a breadth of content within ME 325. However, while it would likely not be possible to offer as much variety, it would be possible to staff a modularized ME 325 course with a single instructor. The ME 325 modules are designed to be offered individually, and would still be taught that way if a single instructor taught multiple modules. The advantage of having a modularized format in these circumstances would be the potential to have multiple "tracks", each covering a different area of that particular instructor expertise.

\section{Collaborative Instructional Design}

\section{Working Together, Part I: Establishing common features}

When discussing modular course design, Andrea Henne, Dean of Online and Distributed Learning in the San Diego Community College District, cites expedited course creation and consistency for users as two advantages of a modularized process. ${ }^{2}$ Both of these benefits arise from using having a common course structure. A common course structure provides a framework for the instructors when developing the course, making course development more efficient. It also provides recurring features to help students understand the structure of the courses. Students appreciate such recurring features, and have even begun to demand them. In the 2013 Educause Study of Undergraduate Students and Information Technology, students' open-ended responses to questions about what institutions could do to improve students' experiences with technology, comments calling for course standardization were a "somewhat common refrain." One example was a student comment that noted that "Every professor likes to set up things differently, so it takes a great deal of time to get acquainted with their setup. If all teachers use the same structure, this problem would be eliminated."

In order to realize the benefits of having common course features, it is necessary to identify features that are going to be consistent across courses.

For our courses, the features that will most likely be common to all courses would be:

1. The overall look and feel of the site. Having a common visual identity helps tie the modules together in the minds of students. It also gives the course a more professional look because it makes it feasible to use a visual identity created by someone who specializes in design. Each module has a unique logotype, but all of the modules have common visual elements. In the case of ME 325, there is consistent use of colored titles within the course itself, and a "hand drawn" format for the slides. The logotypes also use 
this visual approach, and have complementary color schemes.

2. The structure of the module introduction. The introduction to a course must do certain things, regardless of what the course is. It must introduce the student to the course and its instructor and give the student a sense of how the course will be structured. It must also explain the modular structure for students not experienced with it, and lay out the prerequisites to ensure that they have been met.

The features that are be common to analytical modules are:

1. The structure of the course. Currently, the course has a set of units, each of which begins with an overview of the material to be covered, covers a set of topics, with video overviews of the major topics and readings, a sample problem with solution, and a graded assessment activity. At the end of the module a final exam covering all of the material in the module is administered.

\section{Working Together, Part II: Coordinating Between Sections}

Deciding how the individual modules will be structured and assessed is a collaborative process. While individual instructors will teach each individual module of ME 325, the development process is necessarily collaborative. Just as an instructor using a textbook must know the textbook well in order to use it effectively, an instructor teaching one part of ME 325 must know the other parts well. It is especially important that instructors of modules within a course must coordinate their effort with regard to course objectives and assessments. It will be especially important that instructors of the design modules have a very clear understanding of what the learning objectives are for the prerequisite modules. Understanding how prerequisite modules are being assessed will also be critical for understanding what skills their students are expected to have coming in to the course, and what experiences they have had. These prior experiences will shape what students are prepared to do, and what they expect to do. While this has the potential to add to the workload involved in developing the course, once the objectives and structure have been established, the workload for a single module should be no more than would would be expected for any one-unit course being offered online.

\section{Making Room for Individual Innovation}

With all of the talk about rationalized, streamlined, documented processes, it might seem that there is no room for individual instructors to innovate. In a well-structured course design process, this is not and should not be the case. What is different from a single-instructor course development process is that for this more collaborative approach to course design, variations are not simply a matter of personal preference. The course will have a default approach defined, and variations on that approach should happen because they will provide a specific benefit over the default approach. The instructor will need to be able to define what that benefit is, both to his or her colleagues and to students who have come to expect the default approach. Being able to 
explain why a different approach is a better approach requires a clear understanding of what learning objectives and how the learning objectives are being met by the course. One advantage to a more collaborative approach is that, because of the coordination necessary to ensure that learning objectives are being met, it is more likely that an instructor will have the explicit understanding of his or her approach to the course necessary to build an effective argument. Additionally, it is important to ensure that there is room for instructors to make such arguments. Continuing innovation will require that instructors and administrators responsible for providing leadership for the course foster a culture of collaboration. Instructors must feel that it is possible to negotiate successfully, or else they won't bother, and instructors who wish to do innovative work will avoid courses with this type of structure.

\section{Conclusion: Looking Forward}

As more instructors join the project, it will become more necessary to make explicit decisions about how the collaborative process will work. This is intended as a preliminary look at how that process has worked and can work going into the future. The issue of collaboration and negotiation between instructors and administrators will continue to become more important as innovations in educational approaches and the continuing move online make collaborative instruction more common and more necessary.

\section{Bibliography}

1. "Mechanical Engineering Program Educational Objectives" http://www.me.iastate.edu/students/programeducational-objectives-student-outcomes/\# 28 Sept. 2014. Web. 28 Sept 2014.

2. Kelly, Rob. "A Modular Course Design Benefits Online Instructor and Students." Faculty Focus. N.p., 15 Sept. 2009. Web. 14 July 2014.

3. Dahlstrom, Eden, J. D. Walker, and Charles Dziuban. ECAR Study of Undergraduate Students and Information Technology, 2013. Boulder, CO: EDUCAUSE Center for Analysis and Research, 2013. Web. 28 Oct. 2013. 